\title{
Comparison of Naming Methods of Urban and Rural Place Names
}

\section{—Taking Liuzhou City and Luzhai County as Examples}

\author{
Zheng $\mathrm{Li}^{1, \mathrm{a}}$, Guo Jiajia ${ }^{2, \mathrm{~b}^{*}}$ \\ ${ }^{I}$ college of humanities, Minjiang University, Fuzhou,Fujian, China \\ ${ }^{2}$ college of humanities, Minjiang University, Fuzhou,Fujian, China \\ a165248510@qq.com \\ b*736333960@qq.com
}

\begin{abstract}
By comparing the place names of Liuzhou City and Luzhai County, the differences in the naming methods of place names between urban and rural areas and the cultural connotations reflected therein are shown. From the way of naming, the proportion of urban names named by mountains and rivers is high, and the proportion of rural names named by animals and plants is high. The proportion of place names reflecting historical, economic, religious and other factors in urban areas is high, while the place names of villages and towns are more national. The differences in naming methods reflect the differences in economy, politics, values and customs between urban and rural areas.
\end{abstract}

Keywords: urban and rural place names, naming methods, cultural connotation, compare

\section{城乡地名命名方式对比 以柳州市和鹿寨县为例}

郑丽 $1, a$ 郭嘉嘉 $2, b^{*}$

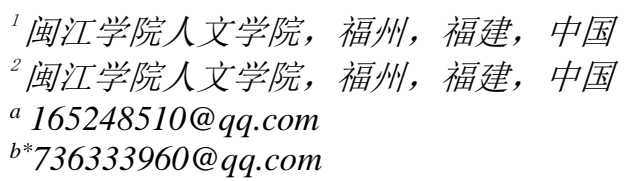

\section{摘要}

通过柳州市和鹿寨县的地名对比，展示城乡地名命名方式的差异及由此体现的文化内涵差异。从命名方式上看， 市区地名以山岭、水系命名比例高, 村镇地名以动植命名比例高; 市区体现历史、工业、商品经济和宗教信仰 等因素的地名更多，村镇地名则更有民族性。命名方式的差异反映了城乡在经济、政治、价值观念及风土人情 等方面的不同。

关键词: 城乡地名, 命名方式, 文化内涵，对比

\section{1. 前言}

地名是语言词汇系统中的一部分，它不仅只是 某一特定区域的符号, 还承载了这一区域的文化信 息，地名的形成或与自然环境有关，或与社会关系 有关。我们以《广面壮族自治区柳州市地名志》和 《广西壮族自治区鹿寨县地名志》为主要语料来源,

辅以柳州地图作为参考, 在搜集、整理柳州市及其 下属的鹿寨县地名的基础上, 对比两地地名命名方 式的不同, 进而从文化学角度解读其背后所蕴含的 社会、民族、历史等文化内涵差异。 


\section{2. 城乡地理环境类命名方式对比}

\section{1 市区的地名以山岭、水系命名的比例高}

地名作为人类社会活动的产物, 其产生与人们 对周围环境的认识有着密切的关系。城市通常诞生 于山地河谷两岸较平坦的地区, 柳州市的情况便是 如此。柳州市区东、西、北三面环山，这些山岭虽 较为矮小, 但其形状各具特色, 当地人便依据这些 山岭名字给地物命名, 如映山街、雀儿山路、登山 路、茅山路、九头山路、羊角山路、葡萄山路、蜈 蚣岭路等。柳州市水资源也十分丰富，这也体现在 地名中, 柳州市有不少与水有关的地名, 水文类地 名通常带有 “塘” “洲” “江” “湖” 等字眼, 如 连塘路、雀湖西路、东堤路、沿江路等。

鹿寨县也有以山岭、水系命名的地名, 以山岭 命名的有平山镇、龙岭村、岭背村等; 以水系命名 的, 如晏塘村、草鞋塘村等。但整体来看, 鹿寨县 以山水命名的地名, 对比城区, 比例低。我们也发 现, 鹿寨县与山有关的地名, 较少直接以山名命名, 而是多根据山的形状进行命名。如半边月村, 因村 后的山岭形状为半月形而得名; 九盘村, 则因村后 山岭有九个盘形山坡而得名; 龙屯村, 因村附近的 山峰似龙形而得名; 坡门村, 则由其村前山坡似门 而得名。

\section{2. 村镇地名以动植物命名的比例高}

人类社会的早期, 生产力低下, 又缺乏相关的 科学知识, 对季节的更替, 植物的生长, 动物繁殖、 迁徙等自然现象, 无法正确认识, 自然显得无比神 秘、强大, 于是就产生了自然崇拜。在自然崇拜的 驱动下, 人们使用动植物名称对地物进行命名。

鹿寨土著民族属于古代岭南越人, 他们多尚鬼, 主要以龙、风、鸟、马作为崇拜的对象, 将其作为 部落的标志或保护神, 他们用这些动物命名自己的 居住地, 隐喻了人们的希冀与追求。至今鹿寨的地 名中还有不少以动物命名的, 动物地名以龙、马为 最多。

鹿寨属典型的亚热带季风气候, 气候温暖湿润, 雨量充沛, 日照充足, 有利于种植业的发展。鹿寨 种植的作物有水稻、甘蔗、果树、茶叶、蜜橘、罗 汉果、香料等。鹿寨还有不少以植物命名的, 如花 桃村、桂兰村、木翠村、香梅村、樟木村、莲花村、 枫木村等。鹿寨县的植物地名以樟、兰、木命名的 为多。据统计, 鹿寨地名中以植物命名的约占鹿寨 地名总数的 $7.2 \%$ 。

据统计, 鹿寨县的动植物地名有 55 条, 是当 地地名命名的重要组成部分, 动植物地名占比为 $17.92 \%$ 。柳州市也有以动植物命名的地名, 如茶花 路、红豆路、风凰巷、驾鹤路等, 但从统计数据来 看, 柳州的动植物类地名仅占总地名数的 $7.16 \%$ 。
显然村镇地名以动植物地名的比例高, 究其原因, 主要有二: 一是与需要工业、商业进行支撑的城市 不同, 乡镇发展要依靠的是农业发展, 故而乡镇的 动植物资源也更为丰富, 乡镇居民与动植物的关系 也更为密切。二是城市作为工业与工业文明的载体, 文化发展呈现出多元化, 具有脆弱易变等特点。动 植物地名中往往遗留有自然崇拜的文化, 这种地名 文化, 在文化发展较为单一的乡镇得到了较为完整 的保留, 而在不断发展的城市中则渐渐被取代。

\section{3. 城乡社会文化类命名方式对比}

地名不仅是语言符号, 还是文化符号, 体现了人 们对主、客观世界的认识, 与人们的精神世界密切相 关, 反映了人们的政治思想、伦理道德精神、宗教思 想等等。城乡社会文化类地名, 市区中是比较常见的, 而在鹿寨县则较少。

\section{1. 市区体现祝福祈愿、宗教信仰的地名比 例高}

\section{1. 1. 市区体现祝愿祈福的地名多}

在柳州城区地名中, 有一类高频使用的语素, 如 “兴、富、康、安、福” 等, 体现了人们对富裕、平 安、健康、吉祥等美好的向往和期朌。像兴福路、乐 业路、利业路、新业路、顺业路、兴发路、兴泰路、 振业路等, 直接体现民众对经济高速发展的期望; 泰 和路、富民路、富国路、祥和路、民泰路则反映出人 们对幸福安康生活的渴望。人们在给地物命名时体现 出的祝愿祈福的心态, 还体现在地名的更名上。如柳 州有个老地名 “羊栏”, 这里的 “羊” 并非动物, 在 当地土匪的黑话体系中指 “男子”，“羊栏” 意为关 押男子的地方, 其意显然不美, 后人们取之谐音改为 “香兰”。还如将破城门改为雅儒路, 野鬼桥改为连 塘路, 猪屎巷改为柳新街等。

由这类祝福祈愿类的地名, 可以窥见柳州市的地 名文化多显世俗化以及非个性化。对世俗幸福生活的 向往是城市社会和个人发展的根本动力, 这种向往不 仅体现在城市的外部形象上, 更蕴含在城市地名文化 之中。

而鹿寨县包含祝福祈愿的地名则要比城市少得 多, 仅占乡镇地名总量的 $2 \%$ 。鹿寨县内表达祝福祈 愿的地名多是以祝福国家有关，如爱国村、思民村。 这类地名多是从 1949 年建国后才重新取名的, 且数 量不多, 但也表现了当地人民纯朴的爱国之心。

\section{1.2. 市区与宗教信仰有关的地名多}

宗教是人类社会发展到一定历史阶段时出现的 精神文化产物, 是人类思想意识的体现, 对社会具有 深远、持久的影响。秦始皇统一全国后, 随着中原文 化与广西当地文化交流的不断加深, 汉族人将佛教等 宗教传入柳州, 使当地在保留一定的原始宗教基础上, 
吸纳融合儒、释、道的内容, 形成各地风貌各异的宗 教形式，从而对柳州地名产生了影响。

解放之前, 柳州市区地名包含的宗教因素主要与 道教有关。解放后, 柳州地名中带有一定封建迷信色 彩的宗教因素逐渐裉去, 取而代之的是具有儒家内涵 的地名。像雅儒路、夫子路、文昌路、文惠路、文兴 路, 这些地名都体现了儒家思想文化的内涵。

与柳州市相比, 鹿寨县鲜有与宗教信仰有关的地 名。乡村文化的传统性以及其所处地域的封闭性，使 得这种 “崇拜文化” 局限在村落中, 无法上升为国家 或民族意识, 发展成为有组织的宗教信仰, 故而鹿寨 县少有与宗教信仰有关的地名。

\section{2. 村镇地名更具有民族性}

地名与特定区域居住的民族及当地使用的语言 密切相关, 能体现民族和区域特点。鹿寨县是个多民 族地区，主要分布的少数民族有壮族、瑶族、苗族、 回族等 18 个民族, 在少数民族生活地区, 不少地名 中包含了少数民族语言要素, 相较而言, 壮语地名数 量最多。

以鹿寨村镇地名中常出现的地名用字为例, 如 “六” 字, 壮族人对山麓、山脚地带, 统称为六。从 实际的地名分布看, 村名中带 “六” 字的村落大多靠 山, 村民们依山而居, 村后的山岭可作为村庄的天然 屏障, 保护村庄, 山上的物产也能提供村民生活之需。 这类地名有六云村、六爱村、六老村、六暗村、六云 村、六经村、六长村、六平村、六角村、六南村、六 班村。再如 “那” 字, 它与当地的稻作农业生产紧密 相关。在壮侗语族各语支中, “那” 字表示水田或田 地之意。带 “那” 字的地名大致有以下几种类型： 1 . 说明田地用途的地名, 如那马 (马: 同汉义, 因此块 田地是古代用来养马进贡朝廷而得名)；2. 说明田地 土壤颜色的地名, 如那红, 表示此处田地的土壤呈红 色; 3. 指出田地周边事物的地名, 如那学 (学: 学堂、 学校)。“那” 字地名主要分布在积温、雨水、日照、 土壤都适合水稻生长的地方, 如那学村、那红村、那 闹村、那基村、那马村。表示田地、土地的壮语音译 字，除了写作 “那” 外，也常被写作 “纳、南” 等。 从这些地名中, 我们可以看出当地农耕文化和稻作文 化发达, 田地作为重要的生产资料, 备受重视和珍惜, 人们对田地的类型相当了解, 并做了十分详细的划分。 这些蕴含着农业文化和稻作文化信息的地名, 不仅保 存了当地的民族文化, 而且还显示出当地主要的经济 形态。

从这些包含少数民族语言要素的地名也可以看 出, 其命名地名的习惯与汉语命名地名的习惯, 存在 很大的不同。壮语地名通常由通名加上专名组成, 例 如 “六平” , 后面的 “平” 是专名, 前面的 “六” 是 通名, 汉意为 “平坦的地方”; 而汉语地名的命名习 惯恰好与之相反, 汉语地名以 “专名+通名” 为常。 如果依照汉语地名的命名习惯, 此地名应为“平六”。
而柳州市区, 从历史上看就非壮族等少数民族的 传统聚居地, 故少有少数民族地名。加之民国时期及 解放后, 城市的发展, 产生了大量的新地名, 这些地 名多以汉语命名。

\section{3. 市区地名更多包含历史、经济因素}

\section{3. 1. 市区与历史有关的地名多}

地名还常蕴含着历史因素, 反映历史发展脉落, 它见证着社会的发展和时代的变迁, 相关的历史信息 也镌刻在地名中。柳州城区就有许多时代特色鲜明的 地名: 辛亥革命时期, 出现了民生路（今小南路）、 民权路 (今柳新街) 等体现三民主义思想的地名; 中 华人民共和国成立后，市区则出现了光明路、解放南 路、解放北路等新路名; 像跃进路、红东路、红光路、 红锋路、红阳路、东方红街 (今窑埠街) 、赤卫路 (今 西闸巷)、奋发路 (今大同巷)、图强路 (今维新巷)、 反帝路 (今鹅岗路) 等地名也有着强烈的时代气息和 政治属性, 光看地名也可大致猜测出其命名年代。随 着历史步伐的向前迈进，不少此类路名又都有了新的 名字。地名随着历史的变迁而不断发生改变, 这在市 区的地名中表现得尤其明显。

而鹿寨县的地名则更为稳定性, 变化不似市区地 名这么令人 “眼花缭乱”, 这与乡镇文化的保守性有 一定的关系。

\section{3. 2. 城市与工业、商品经济有关的地名多}

在传统的城市和乡村中, 城市经济以工业经济和 商品经济为主, 而乡村则以农业经济为主, 这也体现 在城乡地名中。柳州是广西最大的工业城市, 工业经 济发展较好, 柳州有不少带有工业色彩的地名, 如柳 工大道、广汽路等。这些地名呈现出强烈的工业气息。 与工业密切相关的一些关键词, 如科技发展、产业兴 盛、经济繁荣等也出现在地名中, 如兴达路、永前路、 振业路、兴业路等。

再如柳州市境内河流通航里程总长 247 公里, 具 有发展水路运输的天然条件, 水运的发展带动柳州市 港口的发展, 这一现象在地名中也有体现。“埠”在 现代汉语中有 “码头”之意, 柳州市区地名中带“埠” 的有谷埠街、窑埠、洛埠街。这些地名体现了市区商 业经济的发达。

这类与商业经济、工业经济有着密切关系的地名, 在工业化、商业化程度较低的乡镇鲜有出现, 但在柳 州市区却比较常见。

\section{4. 村镇地名更多地使用身体部位表方向、 位置}

鹿寨许多村镇的地名会选择借用身体部位的名 词来表示方位, 体现了人们的一种思维方式, 将大自 
然隐喻为人的身体, 相较于 “东、西、南、北、中” 等方位词, 借用身体部位名词表示方位, 可以将自然 地理实体的方位描述得更为通俗、形象, 也体现了人 类思维的形象思维特征。如 “头” 与 “地域的前端、 顶端”、“口”与 “出入通过的地方” 有相似性, 它 们就具备了指示空间坐标中某一处所的功能。如水头 村、江口村, 从这两个村名, 我们可以大致推断出这 两个村庄的位置。还有些地方地名用脸、胸、手、眼 等来命名。这种方位认知和表达习惯, 体现出当地民 众的思维方式和习惯一一他们的思维更偏向形象性, 抽象性的因素少。

与村镇不同的是, 城市地名更偏爱于用方位词 “东、南、西、北、中” 反映方位概念, 据统计, 柳 州市使用方位词的地名约占地名总数 $16.53 \%$, 使用 方位词, 能够最大程度地将地域方位进行最准确、客 观的描述。

\section{4. 结论}

柳州市地名的命名方式主要分为反映地形地貌、 反映经济发展、反映历史政治、反映意识形态四大类。 其中, 地理环境是城市地名命名的基础, 地形地貌类 地名又可以分为山岭地名、水文地名、方位地名, 这 样的命名方式直观的反映了一座城市的自然地理环 境。鹿寨县地名主要以动植物名, 在空间结构上, 用 表身体部位的一般名词来表示方位。从地名语源来看, 鹿寨县地名则体现了民族性的特点。城乡地名命名方 式的差异, 也折射出城乡在社会形态、历史文化、伦 理道德、民俗风情、自然风貌等方面的差异。

\section{REFERENCES}

[1]Hong B.(1997) Study on Place Names of Zhuang Language in Liuzhou. Guangxi Ethnic Studies,48:111-114.

[2]Qin F,Lin Y.(2007) Language and Culture of Zhuang Place-names.Guangxi People Publishing House,Nanning.

[3]Qin F.(2012)The imprint of ethnic blending-Historical Levels of Place Names in Liuzhou. Guangxi Ethnic Studies, 107:98-102.

[4]Li,J.F.(2004) Chinese Place Names and Multicolor Culture. Shanghai Dictionary Publishing House,Shanghai.

[5]Yang,G.Y.(1991)A Brief Introduction to Toponymy. Northeast Normal University Press,Changchun. 